\title{
SPECIFICS OF MORAL CHOICES MADE BY CHILDREN AGED 6 TO 8 YEARS IN SITUATIONS WITH ETHNOCULTURAL CONTEXT
}

\author{
Dr. Irina V. Sushkova, Chair of Pre-School and Special Education, Bunin Yelets State University, Yelets, Russia \\ E-mail: sushkovairi@yandex.ru \\ Dr. Evgeniya N. Gerasimova, Bunin Yelets State University, Yelets, Russia \\ E-mail: gerasimovaevge@yandex.ru \\ Dr. Angelica N. Pronina, Chair of Psychophysiology and Educational Psychology, \\ Bunin Yelets State University, Yelets, Russia \\ E-mail: angelicapronina@yandex.ru
}

A R T I C L E IN F O

Original Research

Received: January, 26.2018.

Revised: March, 07.2018.

Accepted: March, 12.2018.

doi:10.5937/ijcrsee1801001S

UDK

37.034-053.5

\begin{abstract}
A B S T R A C T
The paper describes the experimental study of the children's specific moral choices from several perspectives. The quantitative and qualitative results of the study were assessed through comparison of the diverse kinds of correct and incorrect moral choices in children aged 6-7 years old and 7-8 years old, the specifics of these choices revealed through resolving two types of specially designed situations with ethnocultural context, namely the situations requiring the child's personal engagement (situations of moral choice) and depersonalized situations (situations with moral challenges, such as "Continue the sentence").
\end{abstract}

\author{
Keywords: \\ children's moral choices, \\ ethnocultural context situations, \\ diagnostics of the moral choices made \\ by children aged $6-8$, \\ personal engagement, \\ depersonalized situations.
}

(C) 2018 IJCRSEE. All rights reserved.

\section{INTRODUCTION}

A human's ability to assume responsibility for both their own well-being and the well-being of the society is an important indicator of a mature personality. Therefore, the categories of "choice," "freedom of choice," "moral choice" receive a special meaning during the early stages of a child's development. True morality is determined by the ability to make free, independent, unforced and voluntary choice that involves sacrificing or neglecting one's personal benefit in favor of an act or deed of high moral value.

Corresponding Author

Dr. Angelica N. Pronina, Bunin Yelets State University, Yelets, Russia

E-mail: angelicapronina@yandex.ru

This work is licensed under a Creative Commons Attribution - NonCommercial - NoDerivs 4.0. The article is published with Open Access at www.ijcrsee.com
A moral choice is a moral act of independent and conscious preference of a specific mode of behavior or choice of action based on the person's moral decision. This means that moral rules urge a person to choose the morally justified side, i.e. to do good, sometimes against one's own interests, desires or needs. The terms "moral choice" and "ethical decision" are often used interchangeably. The authors believe that moral choice is the process of choosing based on moral decision-making when presented with alternative actions, with an aim to prefer one of such actions. The result of the moral decision made by a particular person is therefore his/her moral choice.

The situations generating a conflict between alternative actions that are grounded on "good" or "evil" are the situations of moral choice. A situation of moral choice takes place when the interests of other people, despite conflicting with the interests of the child, are attributed with higher moral value that the child's own ones.

Children's opportunities for indepen- 
dent moral-driven activities are very limited in real life, so situations of moral choice create a tool for expanding the area where the child can demonstrate imagined or real moral-driven behavior.

Since persistent manifestations of correct moral choices make an indicator of fairly high moral standards, it is very important to start providing pedagogical support in developing abilities for such choices as early as in childhood, especially in the age between 6 and 8 years old. The research conducted over the past few years suggests that the psychosocial development of modern children has intensified, and so the descriptions of age-specific traits in children offered decades ago are no longer consistent with today's results of the observation of children's behavior (Savenkov, 2015). This calls for the expansion and clarification of scientific beliefs about age-specific characteristics of moral choice made by children aged 6-8, as well as for identification and differentiation of the specifics of such choices in groups of children aged 6-7 and 7-8. This could contribute to the concept of factoring these specifics into the process of pedagogical regulation of moral choices in preschool and primary school-aged children.

The study of the specifics of moral choices made by children in situations with ethnocultural context is important in terms of addressing the challenges in the ethnocultural education of children in the modern world full of interethnic risks and conflicts.

The logics behind the study of the specifics of moral choices of children aged 6-8 consisted of the following steps: identifying the purpose, hypothesis and methods of study; selecting, analyzing and designing situations of moral choice and situations with ethnocultural context, with the subsequent integration of both moral and ethnocultural contexts; grouping these situations by types and kinds; designing and performing the diagnostics of the moral choices made by children aged 6-8; analyzing, processing and interpreting the results of the diagnostics; identifying special aspects of the moral choices made by the children in situations with ethnocultural context; formulating findings and practical guidelines along with choosing possible prospective paths for studying this problem in future.

\section{LITERATURE REVIEW}

Various aspects of human moral decision-making and the ways of using situations of choice to solve moral problems are covered in the Russian works on philosophy, psychology and pedagogy. Moral choices are examined in different contexts (such as folklore, Islamic traditions, politics, teenage subcultures, etc.). Although the problem of children's moral decision-making is by no means new, it remains under discussion in relation to the early stages of a child's development.

I. Znamenskaya, I. Sozinov and Y. Aleksandrov (2013) have proved that at the early stages of ontogeny (3-6 years old), children rely in their moral choices on intuitive criteria, whereas between 7 and 9years of age they employ the rational choice components that begin to shape at that age.

O. Panfilova (2015) established and unraveled the connection between different types of ethical situations and the moral behavior of primary school-aged children. She identified the stages of the technology used to model situations with different choices of behavior.

There has been some research into the moral and ethical assessment mechanisms in primary school age, based on which it is possible to model situations of moral choice (Kalinina, 2014). N. Laricheva (2015) demonstrated that through the analysis of the situations of moral choice as depicted in fiction, it is possible to prepare primary school-aged children for moral decision-making in resolving reallife situations.

The availability of moral choice for children of primary school age has been observed by a number of researchers (Sushkova and Gerasimova, 2017a, 2017b; Sushkova and Malyutina, 2015, 2016). The ability to make moral choices in children of this age forms as part of the developing moral assessment activity of their mind and is triggered by the need for approval and acceptance. D. Kirilina (2016) established that children with adverse sociometric conditions tend to make more positive moral choices than children with favorable sociometric conditions.

I. Sushkova and Ye. Malyutina (2015) analyzed the phenomenon of "situation" and created groups of situations for social and personal development of schoolchildren by types, kinds and subcategories, which include situations of moral choice. The authors consider such situations to be part of the technology of social and personal development of preschoolers (Sushkova and Malyutina, 2016). The educational potential of problem-based pedagogical situations in the formation of moral concepts in preschool-aged children and the ways to model such situations are dis- 
cussed in the works by Yu. Lavrinyuk (2017), L. Pakhomova, N. Kondratyeva, N. Samodelova (2017). The literature describes possibilities of using the situations of moral choice for designing regional models of ethnocultural education of preschoolers (Sushkova and Gerasimova, 2017a, 2017b) and for diagnosing the motivational component of their social success (Pronina, Yakovleva and Sushkova, 2017).

The foreign literature highlights the issues of moral decision-making in the context of the Christian view of ethics (Scheid, 2015), Islamic morality (Lovat, 2016), and the state standards of school initiatives on the development of moral ideals in children (De Ruyter and Steutel, 2013). I. Chigrinova (2013) dwelled on the core perceptional paradigms of the interpretation of moral choice in modern cognitive psychology. She evaluated the strong and weak points of each paradigm and suggested the ways to tackle the existing contradictions by virtue of the concept of the integrity of a person's intellectual and personal potential. C. Moore and A. Tenbrunsel (2014) looked into the dependency between the cognitive complexity and moral choice. They established that decisions that were made based on contemplations at low and high levels of cognitive complexity are less moral than those made based on contemplations at medium levels of complexity.

R. McDermott and P. Hatemi (2017) revealed the effect caused by a person's level of aggression on his/her foreign policy decisions and moral choices. Other authors studied the link between people's moral judgements and the digital context when using smartphones in situations of moral choice (Barque-Duran, Pothos and Hampton, 2017). R. Burr (2014) showed in her ethnographical study that the concept of a "good child in Vietnam" largely depends on the circumstances and expectations of a particular family, while the moral choice of such children is determined by the acknowledgement of their position in the family hierarchy and their willingness to subordinate their own individual needs to the collective good. R. L. Johnson, J. Liu and Y. Burgess (2017) developed a summarized model of ethical decision-making, which can be applied to the resolution of ethical dilemmas associated with student assessment. The elements of this model include a critical incident giving rise to the ethical dilemma; identification of the conflict elements; decisions about the ethicality of the elements; justification of the decisions; implications; and alternative suggestions.
S. Hertz and T. Krettenauer (2014) researched into the effect of emotions on children's moral choices and found out that the anticipation of moral emotions predicted an increased likelihood of moral choices in antisocial and prosocial contexts. In younger children, anticipated moral emotions predicted moral choice for prosocial actions, but not for antisocial actions.

Summing up what has been said, despite a certain level of the current focus of researchers on the problem of moral choices in children, some questions remain understudied, such as the relation between the moral and ethnic/cultural components of situations of choice; specifics of moral choices made by children aged 6-8 in such situations; the agespecific differences in the moral choice outcomes and their motivations. There is also no scientific opinion about the diversity of moral choices in children aged 6-7 and 7-8, as well as about the relations between different kinds and types of moral choices in children aged 6-7 and 7-8 in different situations with ethnocultural context.

Therefore, the research into the specifics of moral choices made by children in situations with ethnocultural context will help expand the scientific ideas about age-specific characteristics of moral choices in groups of children aged 6-7 and 7-8. Academic literature does not offer any information on differentiated approaches to the pedagogical regulation of moral choices of children aged 6-7 and 7-8 depending on the kinds of those choices.

For that reason, the research hypothesis here consisted in the postulate that the moral choices made by groups of children aged 6-7 and 7-8 have certain specifics which can eventually lay the foundation for the pedagogical regulation of those choices. The purpose of the study is to identify, compare and analyze the specifics of moral choices made by children aged 6-7 and 7-8 in resolving situations with ethnocultural context.

\section{MATERIALS AND METHODS}

The empirical study undertaken in 2017 involved 120 children of preschool and primary school age $(n=120)$ who were attending educational facilities (60 children aged 6-7 y.o. and 60 children aged 7-8 y.o.) in Moscow, Yelets and Lipetsk, and across the Lipetsk Region. The age range was min. 6 and max. 8 .

The scientific background for the experimental study (pedagogical diagnostic) lay in 
the research into the early elements of moral perception in children aged 6-7, which had been conducted earlier by I. Sushkova (2017).

To provide a practical basis for the study, the authors designed two kinds of imaginary situations with ethnocultural context. The situations of the first kind were the situations with the personal engagement of a child. The situations of the second kind were depersonalized situations.

The situations of the first type (situations with the child's personal engagement) included situations of the following two types:

Type 1 covers "situations of preference," which involve the need to choose a nationality which is identical to one's own; a nationality which is different to one's own; or show equal preference ("Imagine you entered a bus and inside you see two vacant seats - one beside a Russian man (the nationality here should be identical to the child's own), and another one - beside a curly-haired, dark-skinned man. Which one will you sit with? Why?). Such situations are modifications of similar situations suggested in various tolerance tests.

Type 2 covers situations of moral choice illustrating various moral ethnocultural-based collisions with multiple choices. The content of such situations activates the children's knowledge about moral norms and behavior rules in respect to a person whose nationality is different from theirs, and at the same time brings on alternative scenarios where their personal interests are respected or neglected in an imaginary way. The dialectically significant content of these situations reflects pairs of opposites in terms of morality (mercy vs. insensitivity, mutual help vs. selfishness, politeness vs. rudeness, and so on), for example, "Imagine you went outside to play football with your mates in the yard and saw your best friend bully a Tajik child (the nationality here should be different from the child's nationality) who has recently moved here from Tajikistan and lives in your house. Your friend won't let the newcomer play with him, he makes fun of him, calls him names just because his appearances of a Tajik boy are different from the way Russian people look. What will you do? Why?" The use of these situations was based on the method of diagnosing the early elements of moral perception in children aged 5-6, which was previously developed by I. Sushkova (2017).

The Type 2 situations (depersonalized situations) include situations with an integrated moral and ethnocultural content. These situations were devised based on the modified
"Continue the sentence" method (Saks-Sidney) enriched with some ethnocultural context ("If children pick on or bully a child dressed in ethnic clothes (e.g. a girl wrapped in a large veil that leaves only eyes uncovered and is called hijab), then ..." "Why?").

Children were offered to solve 12 situations of Type 1 ( 6 situations of the first kind and 6 situations of the second kind) and 6 situations of Type 2, and then answer the question "Why?" The experiment was being conducted with each child individually, in three phases. During the first and second phases, the children would be solving the situations of Type 1 (the situations with the children's personal engagement), of which in the first phase -6 situations of preference, and in the second phase 6 situations of moral choice. During the third phase, the children were offered the situations of Type 2 (depersonalized situations), specifically 6 situations of the kind "Continue the sentence."

After the children solved the situations of moral choice and suggested their solutions to the depersonalized "Continue the sentence" situations, all choices made by each child were classified by the type and kind suggested earlier by I. Sushkova (2017).

The "correct" type of moral choice includes the following kinds: positive, trade-off, partially positive. The "incorrect" type of moral choice includes the following kinds: declarative, partially negative, disguising, negative. The third type of moral choice is hesitative. The kinds of choices were grouped by their degree of the expressiveness of moral significance. The list of the kinds of moral choices given below is in the descending order of this significance - from the most significant one from the perspective of morality to the one completely lacking that significance.

Positive choice is a clear choice made independently by the child in favor of going for a morally valuable action, deed, attitude, often involving either waiving the child's own interests and needs or somehow prejudicing them.

Trade-off choice is a mutually beneficial resolution of the situation when the need to pursue personal interests does not interfere with morally oriented actions and deeds.

Partially positive choice allows the child to combine morally positive behavior with pursuing his/her own interests and needs.

Hesitative choice encompasses the child's doubts when he/she responds, "I don't know."

Declarative choice involves the child's 
verbalization of a certain moral norm or behavior rule without making the actual personal choice (such as "We are supposed to help people!").

Partially negative choice is a choice of the child's own interests with some slight consideration for the needs of the others.

Disguising choice (disguise) is about avoiding a direct rejection in an attempt to disguise it; a conscious wish to evade a negative answer.

Negative choice is an unequivocal rejection of a morally valuable action, deed or attitude, often with an intention to pursue one's own personal interests, etc.

Each kind of choice made was awarded a certain number of points: positive -8 points, trade-off -7 points, partially positive -6 points, hesitative -5 points, declarative -4 points, partially negative -3 points, disguising -2 points, negative -1 point.

The differences between the kinds of moral choices in different types of situations in children aged 6-7 and 7-8 were identified using the Wilcoxon-Mann-Whitney test.

Each kind of choice made by a child in situations of preference was awarded points depending on the degree of moral significance attached to this choice: equal preference- 3 points, preference of a nationality which is different from one's own -2 points, preference of a nationality which is equal to one's own -1 point.

The most significant kinds of preference are the equal preference and the preference of a nationality which is different from one's own. The least significant kind of preference is the preference of a nationality which is equal to one's own. To measure the correlation between the results of solving situations of preference and the types of moral choices in children aged 6-8, the types of moral choices were rated in the following manner: correct 2 points, incorrect -0 points.

The correlation between the results of solving situations of preference and the types of moral choices in children aged 6-8 was established using the Spearman's nonparametric rank correlation coefficient (p).

\section{RESULTS}

The total number of choices made by 60 children aged 6-7 was 1,480 (360 - in situations of preference, 360 - in situations of moral choice, 360 - in "Continue the sentence" situations). The total number of choices made by 60 children aged 7-8 was 1,480 (360 - in situations of preference, 360 - in situations of moral choice, 360 - in "Continue the sentence" situations).

The results of the study are given in the Tables 1, 2, 3, 4, 5 below.

Table 1. Kinds of children's choices in situations of preference

\begin{tabular}{lcccc}
\hline \multicolumn{1}{c}{ Kind of choice } & \multicolumn{2}{c}{$6-7$ y.o. } & \multicolumn{2}{c}{$7-8$ y.0. } \\
\hline $\begin{array}{l}\text { Preference of a } \\
\text { nationality which } \\
\text { is identical to } \\
\text { one's own }\end{array}$ & 234 & $65 \%$ & 124 & $34.44 \%$ \\
\hline $\begin{array}{l}\text { Preference of a } \\
\text { nationality which }\end{array}$ & 42 & $11.67 \%$ & 54 & $15 \%$ \\
$\begin{array}{l}\text { is different from } \\
\text { one's own }\end{array}$ & & & & \\
\hline Equal preference & 84 & $23.33 \%$ & 182 & $50.56 \%$ \\
\hline Total: & 360 & & 360 & \\
\hline
\end{tabular}

The table shows that in the age group of 6-7 years, the prevailing choice is the preference of a nationality which is identical to one's own (65\%), while in the age group of 7-8 years it is an equal preference. At the same time, the differences between the percentages of children preferring a nationality which is different from their own in these age groups were insignificant $-11.67 \%$ and $15 \%$ respectively. In the group of children aged 7-8, the number of equal-preference choices increases noticeably (more than doubles) compared to the group of children aged 6-7 (50.55\% compared to $23.33 \%$ ).

Table 2. Types and kinds of moral choices in children aged 6-7 and 7-8 made in situations with the child's personal engagement and in depersonalized situations

\begin{tabular}{lcccc}
\hline $\begin{array}{c}\text { Types and } \\
\text { kinds of } \\
\text { moral choice }\end{array}$ & $\begin{array}{c}\text { Situations with } \\
\text { the child's } \\
\text { personal } \\
\text { engagement: } \\
\text { (situations of } \\
\text { moral choice) }\end{array}$ & $\begin{array}{c}\text { Depersonalized } \\
\text { situations } \\
\text { ("Continue the } \\
\text { sentence" } \\
\text { situations) }\end{array}$ \\
\cline { 2 - 5 } & $\begin{array}{c}6-7 \\
\text { y.o. }\end{array}$ & $\begin{array}{c}7-8 \\
\text { y.o. }\end{array}$ & $6-7$ y.o. & $7-8$ y.o. \\
\hline Correct type & 222 & 276 & 276 & 324 \\
\hline Positive & 198 & 210 & 252 & 300 \\
\hline Trade-off & 24 & 48 & 24 & 24 \\
\hline $\begin{array}{l}\text { Partially } \\
\text { positive }\end{array}$ & 0 & 18 & 0 & 0 \\
\hline $\begin{array}{l}\text { Hesitative } \\
\text { type }\end{array}$ & 0 & 6 & 6 & 0 \\
\hline $\begin{array}{l}\text { Incorrect } \\
\text { type }\end{array}$ & 138 & 78 & 78 & 36 \\
\hline Declarative & 12 & 6 & 24 & 30 \\
\hline $\begin{array}{l}\text { Partially } \\
\text { negative }\end{array}$ & 12 & 24 & 0 & 0 \\
\hline Disguising & 18 & 18 & 18 & 6 \\
\hline Negative & 96 & 30 & 36 & 0 \\
\hline $\begin{array}{l}\text { Total } \\
\text { choices }\end{array}$ & 360 & 360 & 360 & 360 \\
\hline
\end{tabular}


The total numbers of correct and incorrect types of moral choices in children aged 6-7 are 498 correct ones and 216 incorrect ones (i.e. $69.17 \%$ and $30 \%$, respectively), while in children aged7-8it is 600 correct ones and 114 incorrect ones (i.e. $83.33 \%$ and $15.83 \%$, respectively). In other words, the majority of children aged 6-8 demonstrated the ability to make the correct moral choice in an imaginary situation, both in situations with the child's personal engagement and in depersonalized situations. In the age group of 7-8y.o. this ability is stronger in situations of the kind "Continue the sentence." It is reasonable to assume that this is explained by the child's disinvolvement in such situation, which obviously makes it easier for him/her to make the choice. At the same time, judging from the results of the diagnostics, one can conclude that the personalization of the situations of moral choice drives down the corresponding positive results in children aged 6-7 and 7-8 compared to "Continue the sentence" situations. The impersonal nature of "Continue the sentence" situations, on the other hand, increases the number of positive results in children aged both 6-7 and 7-8.

None of the children aged 6-7were capable of making a partially positive choice, both in situations of moral choice and in situations of the kind "Continue the sentence." None of the children aged 7-8 made the partially positive choice in "Continue the sentence" situations.

Children aged both 6-7 and7-8are able to offer a trade-off as a solution in situations with ethnocultural context. In children aged $7-8$, this capability is higher in situations of moral choice.

There is a certain alignment of the number of incorrect choices and the number of negative choices of this type. In the age group of 6-7 y.o., when presented with situations of moral choice, children tended to make the choice of this kind about three times as more often as in the age group of 7-8 y.o.

Some parts of both groups did make incorrect moral choices, but in the group of children aged 7-8 there were much less of such choices in situations of the kind "Continue the sentence." The greatest number of children who made incorrect choices was recorded in the age group of 6-7y.o. in situations with the children's personal engagement (the situations of moral choice). This is apparently related to the concrete character of the situation in which the child's persona gets to participate.

The disguising kind of choice in situ- ations of moral choice was made in equal quantities by children of both 6-7 years and 7-8 years. However, in situations of the kind "Continue the sentence" in the group of children aged 7-8, the number of choices of that kind was made three times less often.

Children aged 6-7 made the declarative kind of choice in situations of moral choice twice as many times as children aged $7-8$. Children aged 7-8 made the declarative choice more often in depersonalized situations. In "Continue the sentence" situations, the difference in the number of such choices between children of 6-7 years and children of 7-8 years is small. This probably has to do with the lack of personalization in these situations, which prompts the children to make declarative statements.

Zero or quite low number of partially positive and hesitative moral choices in children aged 6-7 are probably attributable to the inclination to unambiguity and clarity in answers, the incapability of offering half-way solutions, which is very characteristic of older preschoolers.

The partially negative choices in situations with the children's personal engagement were made twice as more often by children aged 7-8 as compared to children aged 6-7. The completely missing partially negative choice in "Continue the sentence" situations in groups of both 6-7 y.o. and 7-8 y.o. indicates that the depersonalized nature of situations of this type does not provide any incentives for finding a partial solution.

Table 3. Difference in kinds of moral choices in different types of situations between children aged 6-7 and 7-8 (according to the Wilcoxon-Mann-Whitney test)

\begin{tabular}{lll}
\hline & \multicolumn{2}{c}{$7-8$ y.o. (n=60) } \\
\cline { 2 - 3 } & $\begin{array}{l}\text { Moral choices } \\
\text { in situations } \\
\text { with a child's } \\
\text { personal } \\
\text { engagement: } \\
\text { (situations of } \\
\text { moral choice) }\end{array}$ & $\begin{array}{l}\text { Moral choices } \\
\text { depersonalized } \\
\text { situations } \\
\text { (situations of } \\
\text { the kind } \\
\text { "Continue the }\end{array}$ \\
$\begin{array}{l}\text { Moral choices in } \\
\text { situations with a } \\
\text { child's personal } \\
\text { engagement: } \\
\text { (situations of }\end{array}$ & $1,536.3 *$ & $1,532.7 *$ \\
moral choice) & & \\
\hline $\begin{array}{l}\text { Moral choices in } \\
\text { depersonalized } \\
\text { situations } \\
\text { (situations of the } \\
\text { kind "Continue } \\
\text { the sentence") }\end{array}$ & $1,490.1 *$ & $1,501.6 *$ \\
\hline \multicolumn{1}{c}{$*$ given p $=0.05$} & & \\
\hline
\end{tabular}


The results provided in the table show that the verifiable differences in the kinds of moral choices between the groups of children aged 6-7 and 7-8 do exist.

Table 4. Correlation between the results of solving situations of preference and the types of moral choices made by children aged 6-8, the complete sample $(\mathrm{n}=120)$ (Spearman's rank correlation coefficient, $p$ )

\begin{tabular}{ll}
\hline & $\begin{array}{l}\text { Types of moral choices in } \\
\text { situations with moral } \\
\text { challenges (situations of } \\
\text { moral choice and } \\
\text { situations of the kind } \\
\text { "Continue the sentence") }\end{array}$ \\
\hline $\begin{array}{l}\text { The results of solving } \\
\text { situations of preference } \\
\text { (equal preference, the } \\
\text { preference of a } \\
\text { nationality which is } \\
\text { different from one's } \\
\text { own, the preference of a } \\
\text { nationality which is } \\
\text { identical to one's own) }\end{array} \quad 0.188$ (*with p = 0.05) \\
\hline
\end{tabular}

The results provided in Table 4 point to the existence of the correlation between the results of solving situations of preference and the types of moral choices in children aged 6-8.

The study has shown that the correct and incorrect types of moral choices in children are in a certain correlation with the results of solving situations of preference by children aged 6-8.

Table 5. Correlation between correct/incorrect types of moral choices and the results of solving situations of preference by children aged 6-8 y.o.

\begin{tabular}{ll}
\hline $\begin{array}{l}\text { Number of kinds } \\
\text { of choices in } \\
\text { children aged 6-8 } \\
\text { in situations of } \\
\text { preference }\end{array}$ & $\begin{array}{l}\text { Number of correct and incorrect } \\
\text { choices made by children aged } \\
\text { ch-8 in situations with moral } \\
\text { choice and situations of the kind } \\
\text { "Continue the sentence") }\end{array}$ \\
$\begin{array}{l}\text { Preference of a } \\
\text { nationality which } \\
\text { is identical to } \\
\text { one's own: } 358\end{array}$ & \\
\hline $\begin{array}{l}\text { Preference of a } \\
\text { nationality which } \\
\text { is different from } \\
\text { one's own: } 96\end{array}$ & \\
\hline Equal preference: \\
266
\end{tabular}

The table demonstrates that the total number of correct moral choices is well above the number of incorrect ones. The total number of the most morally significant preferences, namely the preference of a nationality which is different from one's own and equal preference also exceeds the number of preferences of a nationality which is identical to one's own.

In the group of children aged 6-7, the number of correct moral choices (498) is above the number of incorrect ones (216). That said, the total number of the most morally significant preferences, namely the preference of a nationality which is different from one's own and equal preference(126 in total) is less than the number of preferences of a nationality which is identical to one's own (234). Therefore, the considerable number of preferences of a nationality which is identical to one's own (234 out of 360) in most cases does not prevent the children from making the right moral choices. In the group of children aged $7-8$, the number of correct choices (600) prevails over the number of incorrect ones (114). This is consistent with the total number of the most morally significant preferences, namely the preference of a nationality which is different from one's own and equal preference (136 in total), exceeding the number of preference of a nationality which is identical to one's own (124).

\section{DISCUSSION}

To sum up the above, the study helped reveal the specifics of moral choices which both children aged 6-8 as a whole and children from age groups of 6-7 y.o. and 7-8 y.o. typically make when solving imaginary situations with ethnocultural context.

The specifics of moral choices which are characteristic of children aged 6-8 include:

- adequate perception of the moral meaning of situations with ethnocultural context;

- a wide range of types and kinds of moral choices;

- differing numbers of types (correct, incorrect) and kinds (positive, partially positive, negative, partially negative, trade-off, hesitative, declarative, disguising) of moral choices in children aged 6-7 and children aged 7-8;

- the prevalence of the correct type of choice in situations of moral choice and situations of the kind "Continue the sentence";

- the existence of the correlation between the results of solving situations of pref- 
erence and the types of moral choices;

- the existence of differences in the results of solving situations with personal engagement (situations of moral choice) and depersonalized situations (situations of the kind "Continue the sentence");

- the absence of "partially negative" choices among the ones chosen in "Continue the sentence" situations whose impersonal nature does not encourage partial solutions; choices;

- the ability to "disguise" negative

- the personal nature of situations of moral choice drives down the number of positive results as compared with situations of the kind "Continue the sentence," whereas the impersonal nature of "Continue the sentence" situations increases the number of positive results in children;

- the particular pedagogical value in the situations with the child's personal engagement (the situations of moral choice) as compared with depersonalized situations (the "Continue the sentence" situations), given that they specifically bear a personal meaning for the child;

- the ability to justify their own choices in the overwhelming majority of the children who participated in the study.

Below are the specifics of moral choices made by groups of children aged 6-7 and 7-8 in solving imaginary situations with ethnocultural context:

\section{6-7 years old}

- the number of correct type choices is convincingly greater than the number of incorrect type choices;

- the absence of partially positive choices both in situations of moral choice and in situations of the kind "Continue the sentence";

- the ability to make trade-off choices in all situations;

- the number of negative choices in situations of moral choice (where the child is personally engaged) is considerably higher ( 3 times as high) than the number of such choices made in depersonalized situations of the kind "Continue the sentence"; choices;

- the ability to "disguise" negative

- the presence of "declarative" choice in the profile of moral choices;

- declarative statements are made twice as often in depersonalized situations without personal engagement;

- the absence or comparatively low number of partially positive and hesitative moral choices can be attributed to the older preschoolers' inclination to unambiguity and clarity in answers, the incapability of offering half-way solutions;

- the prevalence of choices with the preference of a nationality which is identical to one's own in situations of preference;

- the considerable number of preferences of a nationality which is identical to one's own (the least valuable in terms of morality) in most cases does not prevent the children from making the right moral choices.

7-8 years old

- the number of correct type choices is convincingly greater than the number of incorrect type choices;

- the ability to make partially positive choices in situations with personal engagement (the situations of moral choice) combined with the inability to do that in depersonalized situations (the situations of the kind "Continue the sentence");

- the ability to make trade-off moral choices, with an increased number of such choices in situations of moral choice;

- the absence of negative choices in depersonalized situations of the kind "Continue the sentence";

- a significant (threefold) excess of the number of disguising choices made in situations of moral choice, compared to the number of such choices in situations of the kind "Continue the sentence"

- the tendency to make less frequent, compared to children aged 6-7, declarative choices in situations of moral choice. Children aged 7-8 more often make declarative choices in depersonalized situations;

- more frequent cases of partially negative choices in situations with the child's personal engagement as compared to the age group of 6-7.

- the prevalence of equal preference in situations of preference;

- the greater number of correct choices vs. incorrect ones correlates with the higher number of the most significant, in terms of morality, preferences of a nationality different from one's own and of equal preference vs. the number of preferences of a nationality identical to one's own.

The theoretical significance of the undertaken study consists in the contribution to the scientific knowledge about age-specific characteristics of moral choices made by children aged 6-7 and 7-8 in imaginary situations.

The practical significance of the study is laid out below.

Situations of moral choice are some- 
times avoided in children's moral education programs due to the poor awareness among teachers about the rich diagnostic and pedagogical potential of these situations. The situations with different options to choose from, which are available in various teaching aids and recommended for use by teachers, are scarce. Besides, they do not always describe real-life situations of moral choice. In light of this, the situations of moral choice with ethnocultural context designed in the course of this study can supplement the arsenal of educational tools and methods at kindergartens and preschools.

The dissection of the concept of "choice" into the process of the subject's moral activity and its results helps viewing the pedagogical regulation of moral decision-making in children as the differentiation of the control over the process of choosing and its results. The regulation of the process of choosing consists in the activation, guidance and stimulation of the morally oriented brain activity, support or correction of the particular choice; whereas the regulation of the result of choosing consists in its assessment, reorientation and classification into "good" or "evil." Since moral choice is always a product of freedom and independence, its pedagogical regulation belongs to indirect methods of a teacher's work prior to the act of choice (activation of the moral motivation behind the choice), in the process of choosing (guidance, stimulation and support of the choice) and after the act of choice (assessment, reorientation, classification). The pedagogical regulation of moral choice can be implemented through a differentiated approach to children subdivided into groups in accordance with their most frequently made moral choices. Its function is to deliberately administer complex guiding influence over the moral feelings, moral consciousness and moral behavior of children. Its scope includes focusing the child's attention on the cause and effect of a certain choice; activating the independence in moral decision-making; approving correct moral choices; clarifying the negative component in the partially negative, hesitative and trade-off kinds of moral choices; disapproving negative moral choices; analyzing the negative factor in the partially negative, hesitative, disguising and declarative kinds of moral choices; reorienting the partially negative and disguising kinds of moral choices; "breaking" the declarative nature of statements, etc.

Based on the results of the study it is reasonable to assume that the specifics of moral choices characteristic of children in groups of age 6-7 and 7-8 dictate a differentiated approach to the pedagogical regulation of this choice.

For example, in situations with the children's personal engagement in age groups of 6-7 where the number of negative choices is the greatest, the highest priority should be given to the focusing of the children's attention on this kind of choice, to the disapproval and reorientation of this choice. The absence of partially positive choices in this age group prompts the teacher to activate thinking processes in children (through comparing alternative actions, analyzing the situations in an attempt to find possible resolutions, etc.). When guiding the solving of depersonalized situations of the kind "Continue the question" in groups of children aged 6-7 who tend to make a significant number of declarative choices, teachers can focus on "breaking" the declarative nature of their statements, etc. Another promising option would be to initiate pedagogical efforts in forming tolerance towards people of different nationalities. This would help improve the results of the related work on pedagogical regulation of moral choices in situations with ethnocultural context.

\section{CONCLUSIONS}

When solving situations with personal engagement in groups of children aged 7-8 who tend to make three times as many correct choices as incorrect ones, teachers should base their educational work on such methods as the holding of the positive choice as an example, its analysis in terms of morality and the admiration of the child's correct choice. When solving depersonalized situations of the kind "Continue the sentence" in groups of children aged 7-8 who typically avoid negative and partially negative choices, it makes sense to shift the educational focus towards analyzing the negative factors in disguising and declarative kinds of moral choices, reorienting disguising choices, "breaking" declarative choices, etc.

The question remains whether there is any dependency of the results of children's moral decision-making on the ethnocultural aspects determining the context of the situations of moral choice. For this reason, it would be reasonable to do future research on comparing the results of the moral decisions made by children aged 6-7 and 7-8 in situations of moral choice with the integrated moral and ethnocultural context, with the results of deci- 
sions made in situations that lack such context. Further research can also be conducted in the field of studying and differentiating the motives of moral choices in situations with ethnocultural context in children aged 6-7 and 7-8.

Thus, the differentiation of children's moral choice by types and kinds can accordingly help build the differentiated educational process in groups of children aged 6-7 and $7-8$. The results of the study highlight the opportunities to account for the specifics of moral choices in moral education, as well as to supplement both the diagnostic and, in fact, the educational components of this process.

\section{ACKNOWLEDGMENTS}

The study was carried out within the framework of the state task of the Ministry of Education and Science of the Russian Federation (project No. 27.9480.2017/NM "Development of projects for regional ethno-cultural education models, including the content of general and pre-school education aimed at forming ethnic and civic identity and educating interethnic tolerance and patriotism".

\section{Conflict of interests}

The authors declare no conflict of interest.

\section{REFERENCES}

Barque-Duran, A., Pothos, E. M., Hampton, J. A., \& Yearsley, J. M. (2017). Contemporary morality: Moral judgments in digital contexts. Computers in Human Behavior, 75, 184-193. https://doi. org/10.1016/j.chb.2017.05.020

Burr, R. (2014). The complexity of morality: Being a 'good child' in Vietnam? Journal of Moral Education, 43(2), 156-168. https://doi.org/10.1080/ 03057240.2014 .893421

Chigrinova, I. A. (2013). Two principal paradigms of understanding moral choice in contemporary cognitive psychology. Issues of Psychology, 6, 115-124. https://www.researchgate.net/publication/289354063_Two_principal_paradigms of understanding moral choice in contemporary cognitive psychology

De Ruyter, D. J., \& Steutel, J. W. (2013). The promotion of moral ideals in schools; what the state may or may not demand. Journal of Moral Education, 42(2), 177-192. https://doi.org/10.1080/ 03057240.2013 .771118

Hertz, S. G., \& Krettenauer, T. (2014). Children's utilization of emotion expectancies in moral decision-making. British Journal of Developmental Psychology, 32(3), 367-373. https://doi. org/10.1111/bjdp.12052

Johnson, R. L., Liu, J., Burgess, Y. (2017). A model for making decisions about ethical dilemmas in student assessment. Journal of Moral Education, 46(2), 212-229. https://doi.org/10.1080/030572 40.2017.1313725

Kalinina, L. V. (2014). Forming morality-driven values in primary school children through moral and ethical assessment. Siberian Pedagogical Journal, 1, 61-64.

Kirilina, D. O. (2016). Specifics of personal relations with preschool children of the same age in situations with different types of moral choices. The Youth Scientific Forum: Humanities, 11(39), 181-186. http://nauchforum.ru/archive/MNF humanities/11(39).pdf

Laricheva, N. V. (2015). Formation of junior pupils' ability to make a moral choice in solving different life problems. Historical and Social-Educational Ideas, 7(3), 206-210. http://dx.doi. org/10.17748/2075-9908.2015.7.3.206-210

Lavrinyuk, Yu. G. (2017). Educational potential of problem-based pedagogical situations in the process of shaping moral concepts in preschool children. Proceedings of the 6th International Scientific Conference "Innovative Educational Technologies", 37-39. https://moluch.ru/conf/ ped/archive/214/12294/

Lovat, T. (2016). Islamic morality: Teaching to balance the record. Journal of Moral Education, 45(1), 1-15. https://doi.org/10.1080/03057240.2015.1 136601

McDermott, R., \& Hatemi, P. K. (2017). The relationship between physical aggression, foreign policy and moral choices: Phenotypic and genetic findings. Aggressive Behavior, 43(1), 37-46. https:// doi.org/10.1002/ab.21660

Moore, C., \& Tenbrunsel, A. E. (2014). "Just think about it"? Cognitive complexity and moral choice. Organizational Behavior and Human Decision Processes, 123(2), 138-149. https:// doi.org/10.1016/j.obhdp.2013.10.006

Pakhomova, L. V., Kondratyeva, N. M., Samodelova N. Ye. (2017). Solving problem-based situations with junior preschool children. Young Scientist, 45, 248-250. https://moluch.ru/archive/179/46344/

Panfilova, O. V. (2015). Possibilities of Application of Pedagogical Design of Situations of Act Choice in Ethical Education of Junior Pupils. The online journal Naukovedenie, 7(3/28), 1-6. http:// dx.doi.org/10.15862/68PVN315

Pronina, A. N., Yakovleva, I. V., Sushkova, I. V. (2017). Correlation between social success and emotions of preschoolers. Novosibirsk State University Bulletin, 7, 88-103.

Savenkov, A. I. (2015). The development of a child's mentality in early age. A child in the educational space of a metropolis. Proceedings of the II Interregional Research and Practice Conference, 4-8.

Scheid, A. F. (2015). Moral Choice: A Christian View of Ethics. Horizons, 42(2), 482-484. https://doi. org/10.1017/hor.2015.82

Sushkova, I. V. (2017). Moral foundation of the ethnocultural education of preschoolers. Proceedings of the 2nd International Research and Practical Conference "Gnoseological Basis for Education", 468-472.

Sushkova, I. V., \& Gerasimova, Ye. N. (2017a). Designing regional models of ethnocultural education. Psychology of Education in the Multicultural 
Space, 4(40), 108-116. http://elsu.ru/journal/issues/155/articles/2054/

Sushkova, I. V., \& Gerasimova, Ye. N. (2017b). The additional educational program "In the World of Many Nationalities": an ethnocultural education program for preschool children aged 6 to 7 (8) years. Yelets: Bunin Yelets State University Press.

Sushkova, I. V., \& Malyutina, Ye. N. (2015). The phenomenon of "situation" in the pedagogy of socially oriented personal and communicational development of preschoolers. Bulletin of the Eastern Economics and Law Humanities Academy, 1(75), 57-63.

Sushkova, I. V., \& Malyutina, Ye. N. (2016). About the Technology of Social and Personal Development of children of The Late Pre-School Age in Educational Situations. Psychology of Education in the Multicultural Space, 3(35), 130-144. http:// www.elsu.ru/journal/issues/113/articles/1634/

Znamenskaya, I. I., Sozinova, I. M., Aleksandrov, Y. I. (2013). Intuitive and rational components of moral choice in children aged 3-11. Theoretical and Experimental Psychology, 6(2), 57-70. http://www.tepjournal.ru/en/content/2013/vol6-2/06 